\title{
Prevalence and determinants of poor glycaemic control amongst patients with diabetes followed at Vanga Evangelical Hospital, Democratic Republic of the Congo
}

\begin{tabular}{|c|c|}
\hline \multicolumn{2}{|c|}{$\begin{array}{l}\text { Authors: } \\
\text { Lino Masingo Cedrick }^{1} \\
\text { Jean-Pierre Fina Lubaki } \\
\text { Lepira Bompeka Francois }^{3} \\
\text { Ogunbanjo Adebola } \\
\text { Gboyega }^{4} \text { (D) } \\
\text { Lukanu Ngwala Philippe }^{2}\end{array}$} \\
\hline \multicolumn{2}{|c|}{$\begin{array}{l}\text { Affiliations: } \\
{ }^{1} \text { Department of Family } \\
\text { Medicine, Faculty of } \\
\text { Medicine, Protestant } \\
\text { University of Congo, } \\
\text { Kinshasa, Democratic } \\
\text { Republic of the Congo }\end{array}$} \\
\hline $\begin{array}{l}{ }^{2} \text { Department } \\
\text { Medicine and } \\
\text { Care, Faculty } \\
\text { Protestant Un } \\
\text { Congo, Kinsha } \\
\text { Republic of th }\end{array}$ & $\begin{array}{l}\text { f Family } \\
\text { Primary Health } \\
\text { f Medicine, } \\
\text { versity of } \\
\text { sa, Democratic } \\
\text { Congo }\end{array}$ \\
\hline \multicolumn{2}{|c|}{$\begin{array}{l}{ }^{3} \text { Department of Nephrology, } \\
\text { Faculty of Medicine, } \\
\text { University of Kinshasa, } \\
\text { Kinshasa, Democratic } \\
\text { Republic of the Congo }\end{array}$} \\
\hline \multicolumn{2}{|c|}{$\begin{array}{l}{ }^{4} \text { Department of Family } \\
\text { Medicine and Primary Health } \\
\text { Care, Faculty of Medicine, } \\
\text { Sefako Makgatho Health } \\
\text { Sciences University, Pretoria, } \\
\text { South Africa }\end{array}$} \\
\hline \multicolumn{2}{|c|}{$\begin{array}{l}\text { Corresponding author: } \\
\text { Lukanu Ngwala Philippe, } \\
\text { phlukanu@yahoo.fr }\end{array}$} \\
\hline \multicolumn{2}{|c|}{$\begin{array}{l}\text { Dates: } \\
\text { Received: } 12 \text { July } 2020 \\
\text { Accepted: } 13 \text { Mar. } 2021 \\
\text { Published: } 30 \text { Apr. } 2021\end{array}$} \\
\hline \multicolumn{2}{|l|}{ Read online: } \\
\hline 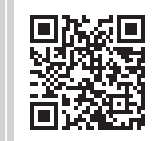 & $\begin{array}{l}\text { Scan this QR } \\
\text { code with your } \\
\text { smart phone or } \\
\text { mobile device } \\
\text { to read online. }\end{array}$ \\
\hline
\end{tabular}

Background: The prevalence of diabetes mellitus is increasing dramatically in developing countries, where diabetic patients usually present with poor glycaemic control, leading to complications and worsening the prognosis.

Aim: The aim of this study was to determine the extent of poor glycaemic control and its determinants in diabetic patients.

Setting: The study was conducted in a rural area of the province of Kwilu, Democratic Republic of the Congo.

Methods: This research comprised a cross-sectional study involving 300 Type 1 and 2 diabetic patients attending Vanga Evangelical Hospital in the Democratic Republic of the Congo from January 2018 to March 2018. Patients' sociodemographic, clinical and biological characteristics, accessibility to the health structure and treatment were described. The determinants of poor glycaemic control were identified using multivariate logistic regression at the $p<0.05$ level of statistical significance.

Results: The mean age of participants was $46.9 \pm 16.3$ years, $68.4 \%$ were men, and $62.3 \%$ had Type 2 diabetes mellitus. Poor glycaemic control was present in $78 \%$ of patients. The independent determinants of poor glycaemic control were tobacco use (adjusted odds ratio [aOR]: 2.01 [1.77-5.20], $p=0.015$ ), the presence of comorbidities (aOR: 2.86 [1.95-6.65], $p=$ 0.007 ), the presence of a factor contributing to hyperglycaemia (aOR: 2.74 [1.83-3.67], $p=$ 0.014 ), missing scheduled appointments (aOR: 2.59 [1.94-7.13], $p=0.006$ ) and non-adherence to treatment (aOR: 4.09 [1.35-6.39], $p=0.008$ ).

Conclusion: This study shows that more than three-quarters of diabetics undergoing treatment are not controlled, with mainly patient-related factors as the main explanatory factors for this poor glycaemic control. Therefore, the establishment of a therapeutic education programme and wider integration of diabetes care services, mainly at the primary level of the healthcare pyramid, should contribute to improved diabetes treatment.

Keywords: determinants; diabetics; glycaemic control; rural; poor; prevalence; patients.

\section{Introduction}

In 2014, the World Health Organization estimated that 422 million people were living with diabetes, a prevalence that had almost doubled from $4.7 \%$ in 1980 to $8.5 \%$ in $2014 .{ }^{1}$ According to the International Diabetes Federation (IDF), the number of people living with diabetes will increase in Africa from 14.2 million in 2015 to 34.2 million in 2040²; demographic and nutritional transitions, as well as rapid and unplanned urbanisation, are some of the explanatory factors for this development. ${ }^{3,4}$ In sub-Saharan Africa, the number of diabetic patients was estimated at 14.7 million in 2011, with 737090 cases in the Democratic Republic of the Congo (DRC). ${ }^{5}$ In Kinshasa, a study conducted in 2000 estimated the prevalence of diabetes to $7 \%$ in adults. ${ }^{6}$ In Kisantu, a semi-urban area in the DRC, the prevalence of diabetes mellitus was estimated at $4.8 \%$ in 2007.7 In Bukavu, Katchunga et al. reported a prevalence rate of 7.3\% in 2012. ${ }^{8}$

How to cite this article: Cedrick LM, Fina Lubaki J-P, Francois LB, Gboyega OA, Philippe LN. Prevalence and determinants of poor glycaemic control amongst patients with diabetes followed at Vanga Evangelical Hospital, Democratic Republic of the Congo. Afr J Prm Health Care Fam Med. 2021;13(1), a2664. https://doi.org/10.4102/phcfm.v13i1.2664

Copyright: ( 2021. The Authors. Licensee: AOSIS. This work is licensed under the Creative Commons Attribution License. 
Adequate glycaemic control is recommended in both type 1 and type 2 diabetic patients to delay the onset of complications, ${ }^{9,10}$ improve the quality of life of patients and at the same time reduce the high cost of diabetes care for the health sector. ${ }^{7,8,10}$ However, as it is with other chronic diseases, very few diabetic patients consult on time to obtain optimal medical intervention and treatment for their diseases because of multiple factors. ${ }^{11}$ The prevalence of poor glycaemic control varies, from $29 \%$ to $73 \%$ in diabetic patients aged greater than or equal to 65 in the United States (US), ${ }^{12} 65 \%$ in France, ${ }^{13} 71 \%$ in East, West and Central Africa ${ }^{14}$ and $68 \%$ in the DRC. ${ }^{15}$ Many factors determine poor glycaemic control in patients, related to diabetes disease and sociodemographic, clinical and treatment characteristics; access to quality care and patient adherence to follow-up recommendations and lifestyle change also play a significant role. ${ }^{16,17}$ Mbanya et al. found, in the International Diabetes Management Practices Study (IDMPS) in 12 African countries, that unhealthy diet, lack of exercise, lack of self-management and hospitalisation in the past 12 months were predictors of poor glycaemic control in both types of diabetes, whilst poor diabetes education and longer duration of diabetes were predictors of poor glycaemic control for only Type $1 .^{18}$

In 2009, a study conducted in Vanga amongst diabetic patients showed that only $34.4 \%$ had optimal or acceptable glycaemic control. ${ }^{19}$ Complications of diabetes are a common reason for outpatient consultations or provision of emergency services at Vanga Evangelical Hospital. For example, a study on ocular complications of diabetes conducted in Vanga in 2014 found that 177 participants $(63.2 \%)$ had at least one ocular complication. ${ }^{20}$ Factors associated with poor glycaemic control vary throughout settings. The objective of this study was to assess the extent of poor glycaemic control and its determinants in type 1 and 2 diabetic patients attending Vanga Evangelical Hospital.

\section{Methods \\ Type of study}

This was a cross-sectional study.

\section{Study period and setting}

The study took place from 01 January 2018 to 31 March 2018 at the Vanga Evangelical Hospital-the Referral Hospital of the Rural Health District of Vanga in the province of Kwilu, in the south-west of the DRC. The health district of Vanga includes 55 health facilities spread over an area of $2600 \mathrm{~km}^{2}$. The Vanga Evangelical Hospital is the sole facility in the area that runs a diabetic clinic. The clinic runs twice a week, providing outpatient services to diabetic patients including education, examination and treatment. The clinic has 1025 registered patients. The average attendance per clinic day was 50 patients. A team of two doctors, three nurses, a pastor and a social worker operate the diabetic clinic.

\section{Study population}

The study population consisted of diabetes mellitus patients attending the Diabetic Clinic of Vanga Evangelical Hospital.

\section{Selection criteria}

All patients with diabetes Type 1 and Type 2, aged 15 years or more, attending the outpatient diabetic clinic for 6 months or longer were eligible for the study.

\section{Sample size}

The sample size was estimated using the Fischer formula of a known population of patients with diabetes (1025), taking into account a $95 \%$ confidence interval (CI) with an expected accuracy of $5 \%$ and a poor glycaemic control rate of $65.6 \%$. The minimum size of 230 patients was estimated. A total of 300 participants were selected.

\section{Sampling}

Selection of the participants was done through systematic sampling. The sampling frame was calculated as $k=1025 / 300$ or 3 . The starting point for inclusion was a number chosen between 1 and $k$; the number 1 was chosen. At each session, a list of patients was drawn up in order of arrival at the clinic. On this list, on each clinic day, the first patient of the day was included in the study, and every third patient after that was included. If the first and third patients were ineligible, the next patient on the list was selected. At each session, the principal researcher or the research assistants interviewed a maximum of four patients. The process was repeated until the desired sample size was attained.

\section{Data collection}

The principal investigator and three trained research assistants performed the data collection. Prior to patients' inclusion in the study, members of the research team explained the purpose and objectives of the study to the mand obtained informed consent. All patients were interviewed with a structured and pretested questionnaire and given a physical examination (performed by the principal investigator with the help of the Vanga Hospital medical team). Early morning blood capillary samples were taken to measure glycosylated haemoglobin (HbA1c) using spectrophotometer from Shenzhen Genius Electronics (Shenzhen, China). The variables of interest in the study were sociodemographic characteristics, accessibility to the health structure, diabetes characteristics and treatment modalities. Poor glycaemic control was defined by a level of glycosylated $\mathrm{HbA} 1 \mathrm{c}$ of $\leq 7.0 \%$, whilst adequate glycaemic control was defined by an HbA1C level of $>70 \%$ and complications and comorbidities considered in the study were those described for patients' record booklets.

\section{Statistical analysis}

The data were encoded using Excel 2010 software; after checking and cleaning the database, the data were exported to Statistical Package for Social Sciences (SPSS) software version 21 (Chicago, IL, US). The statistical data analysis consisted of calculating the means or medians and interquartile ranges (IQRs) or standard deviation (SD) for continuous variables and the frequencies $(n)$ and percentages (\%) for categorical variables. For bivariate analysis, continuous variables were 
transformed to categorical variables (age, duration of the disease, monthly income, household size). Pearson's chisquare or Fischer's exact test were used to compare proportions. Logistic regression was used to assess the determinants of poor glycaemic control; odds ratios (ORs) and their 95\% CIs were used to estimate the strength of association between the independent and dependent variables. A value of $p<0.05$ was set as the statistical significance threshold.

\section{Ethical considerations}

Ethics approval was granted by the ethics committee of the Protestant University of Congo (CEUPC0035).

The protocol was submitted to and approved by the Ethics Committee of the Protestant University in Congo (approval no. CUPC0047). Authorisation to conduct the study was obtained from the hospital authorities. The participants were asked to sign an informed consent form after they were given an explanation of the purpose and objectives of the study and were offered an opportunity to ask any questions regarding the conduct of the study. The participants were assured of their right to withdraw from the study at any time they wished without having to give a reason and without any negative consequences for the care they received at the diabetic clinic. The anonymity of patients and confidentiality of their data were guaranteed at all times.

\section{Results}

The study sample consisted of 300 patients with diabetes, out of 314 patients asked to participate in the study (yielding a non-response rate of $4.5 \%$ ). Men represented $68.4 \%$ of participants, and Type 2 diabetes was more prevalent. The mean age of participants was $46.9 \pm 16.3$ years. The majority of participants were in the 40-59-year age group (44.7\%), married $(72 \%)$, had not attained university education $(91.7 \%)$ and had low income $(56.0 \%)$. The mean distance to reach the health centrewas $32 \mathrm{~km}$ by foot forthe majority of participants $(74.7 \%)$. The mean duration of the disease for the majority of respondents was less than 10 years $(78.7 \%)$. Alcohol intake and tobacco use were noted for $22.7 \%$ and $13.7 \%$ of participants, respectively. More than a quarter of the participants $(27.3 \%)$ had abdominal obesity, and $19.3 \%$ had hypertension. Nearly one-third of diabetic patients (34.0\%) had a factor contributing to hyperglycaemia, amongst which infection was the most prevalent (20\%). Insulin (65.0\%) was the most common treatment, followed by glibenclamide $(29.0 \%)$ and metformin $(26.0 \%)$. Fourteen percent of the patients attended the clinic two or more times every month, and $92 \%$ felt they respected the appointment schedules. Seventy-nine percent of participants felt that they had strictly followed the instructions for taking medication. Poor glycaemic control was observed in $78 \%$ of patients. When comparing the two patient groups constituted by those with adequate versus those with poor glycaemic control in terms of sociodemographic characteristics, only income less than
60 United States dollars (USD) was significant for poor glycaemic control (42.4\% vs. $63.2 \%, p=0.019)$ (Table 1$)$.

Accessibility to the health centre and all its components was not associated with poor glycaemic control (Table 2).

When considering the clinical parameters and treatment characteristics (Table 3), patients with poor glycaemic control comprised a significantly higher proportion of those who were consuming alcohol (26.5\% vs. 9.1\%, $p=0.022)$, smokers (15.0\% vs. $9.1 \%, p=0.015)$, had a diabetes duration of $\geq 10$ years $(26.1 \%$ vs. $4.5 \%, p<0.001)$, had Type 2 diabetes (65.8\% vs. $50.0 \%, p=0.035)$ and had comorbidities (31.6\% vs. $15.2 \%, p=0.017)$, with mainly hypertension ( $23.5 \%$ vs. $4.5 \%$, $p<0.001)$ and heart disease $(17.1 \%$ vs. $1.5 \%, p=0.039)$. They also comprised a significantly higher proportion of poor compliant patients $(23.5 \%$ vs. $4.5 \%, p<0.001)$ and those with fewer than two visits per month $(92.7 \%$ vs. $62.1 \%, p=0.008)$. As patients with Type 1 and Type 2 diabetes showed a difference in diabetes control, we conducted a comparison of these two kinds of patients that showed the difference by level of education $(p=0.03)$ and profession $(p=0.028)$.

Multivariate analysis by logistic regression retained a model with the following independent factors of poor glycaemic control: smoking (adjusted OR [aOR]: 2.01 [1.77-5.20], $p=0.015$ ), the presence of comorbidities (aOR: 2.86 [1.956.65], $p=0.007)$, the presence of a factor contributing to hyperglycaemia (aOR: 2.74 [1.83-3.67], $p=0.014$ ), the

TABLE 1: Participants' sociodemographic characteristcics and poor glycaemic control, Vanga, 2018.

\begin{tabular}{|c|c|c|c|c|c|}
\hline \multirow[t]{2}{*}{ Variable } & \multicolumn{2}{|c|}{$\begin{array}{l}\text { Poor glycaemic } \\
\text { control }\end{array}$} & \multicolumn{2}{|c|}{$\begin{array}{c}\text { Adequate } \\
\text { glycaemic control }\end{array}$} & \multirow[t]{2}{*}{$p$} \\
\hline & $n$ & $\%$ & $n$ & $\%$ & \\
\hline Age (years) & & & & & 0.460 \\
\hline $15-39$ & 73 & 31.2 & 25 & 37.9 & - \\
\hline $40-59$ & 109 & 46.6 & 25 & 37.9 & - \\
\hline $60-88$ & 52 & 22.2 & 16 & 24.2 & - \\
\hline Sex & & & & & 0.209 \\
\hline Man & 160 & 68.4 & 41 & 62.1 & - \\
\hline Woman & 74 & 31.6 & 25 & 37.9 & - \\
\hline Occupation & & & & & 0.594 \\
\hline Unemployed & 44 & 18.8 & 16 & 24.2 & - \\
\hline Independent & 131 & 56.0 & 36 & 54.5 & - \\
\hline Official & 59 & 25.2 & 14 & 21.2 & - \\
\hline Monthly income & & & & & 0.019 \\
\hline$<60 \mathrm{SD}$ & 148 & 63.2 & 28 & 42.4 & - \\
\hline$\geq 60 \mathrm{SD}$ & 86 & 36.8 & 38 & 57.6 & - \\
\hline Educational level & & & & & 0.636 \\
\hline No level & 23 & 9.8 & 3 & 4.5 & - \\
\hline Primary & 65 & 27.8 & 19 & 28.8 & - \\
\hline Secondary & 126 & 53.8 & 38 & 57.6 & - \\
\hline University & 20 & 8.5 & 6 & 9.1 & - \\
\hline Household size & & & & & 0.319 \\
\hline$\leq 6$ & 168 & 71.8 & 50 & 75.8 & - \\
\hline$>6$ & 66 & 28.2 & 16 & 24.2 & - \\
\hline
\end{tabular}

Note: The data are expressed as the mean \pm standard deviation, frequency (absolute) and relative (in percentage).

$N=300$.

SD, standard deviation. 
non-respect of appointment schedules (aOR: 2.59 [1.94-7.13], $p=0.006)$ and non-compliance to treatment (aOR: 4.09 [1.356.39], $p=0.008$ ) (Table 4).

TABLE 2: Accessibility to the health centre and poor glycaemic control amongst diabetic patients, Vanga, 2018.

\begin{tabular}{|c|c|c|c|c|c|}
\hline \multirow[t]{2}{*}{ Variable } & \multicolumn{2}{|c|}{$\begin{array}{c}\text { Poor glycaemic } \\
\text { control }\end{array}$} & \multicolumn{2}{|c|}{$\begin{array}{c}\text { Adequate } \\
\text { glycaemic control }\end{array}$} & \multirow[t]{2}{*}{$p$} \\
\hline & $n$ & $\%$ & $n$ & $\%$ & \\
\hline Means of transport & & & & & 0.121 \\
\hline Motorcycle & 38 & 16.2 & 6 & 9.1 & - \\
\hline Foot & 175 & 74.8 & 49 & 74.2 & - \\
\hline Vehicle & 4 & 1.7 & 3 & 4.5 & - \\
\hline Bicycle & 14 & 6.0 & 8 & 12.1 & - \\
\hline Canoe & 3 & 1.3 & 0 & 0.0 & - \\
\hline $\begin{array}{l}\text { Time taken to reach health } \\
\text { facility (hours) }\end{array}$ & & & & & 0.724 \\
\hline $0-1$ & 57 & 24.4 & 12 & 18.2 & - \\
\hline $2-5$ & 76 & 32.5 & 24 & 36.4 & - \\
\hline $6-24$ & 80 & 34.2 & 25 & 37.9 & - \\
\hline$>24$ & 21 & 9.0 & 5 & 7.6 & - \\
\hline Frequency of visits & & & & & 0.594 \\
\hline Frequent & 119 & 50.9 & 33 & 50.0 & - \\
\hline Occasional & 101 & 43.2 & 31 & 47.0 & - \\
\hline Non-existent & 14 & 6.0 & 2 & 3.0 & - \\
\hline
\end{tabular}

Note: The data are expressed as frequency (absolute) and relative (in percentage). $N=300$.

TABLE 3: Clinical characteristics, treatment modalities and poor glycaemic control amongst diabetic patients, Vanga, 2018.

\begin{tabular}{|c|c|c|c|c|c|}
\hline \multirow[t]{2}{*}{ Variable } & \multicolumn{2}{|c|}{$\begin{array}{l}\text { Poor glycaemic } \\
\text { control }\end{array}$} & \multicolumn{2}{|c|}{$\begin{array}{l}\text { Adequate glycaemic } \\
\text { control }\end{array}$} & \multirow[t]{2}{*}{$p$} \\
\hline & $n$ & $\%$ & $n$ & $\%$ & \\
\hline Alcohol intake & 62 & 26.5 & 6 & 9.1 & 0.022 \\
\hline Tobacco consumption & 35 & 15.0 & 6 & 9.1 & 0.015 \\
\hline Duration of diabetes (years) & & & & & $<0.001$ \\
\hline$<10$ & 173 & 73.9 & 63 & 95.5 & - \\
\hline$\geq 10$ & 61 & 26.1 & 3 & 4.5 & - \\
\hline Type of diabetes & & & & & 0.035 \\
\hline Type 1 & 80 & 34.2 & 33 & 50.0 & - \\
\hline Type 2 & 154 & 65.8 & 33 & 50.0 & - \\
\hline Comorbidities & 74 & 31.6 & 10 & 15.2 & 0.017 \\
\hline Hypertension & 55 & 23.5 & 3 & 4.5 & $<0.001$ \\
\hline Heart disease & 4 & 17.1 & 1 & 1.5 & 0.039 \\
\hline Diabetic retinopathy & 3 & 1.3 & 2 & 3.0 & 0.304 \\
\hline Tuberculosis & 7 & 3.0 & 3 & 4.5 & 0.383 \\
\hline Chronic kidney disease & 3 & 1.3 & 1 & 1.5 & 0.632 \\
\hline Overweight & 43 & 18.4 & 13 & 19.7 & 0.466 \\
\hline Obesity & 11 & 4.7 & 4 & 6.1 & 0.428 \\
\hline \multicolumn{6}{|l|}{$\begin{array}{l}\text { Factors contributing to } \\
\text { hyperglycaemia }\end{array}$} \\
\hline Infection & 50 & 21.4 & 10 & 15.2 & 0.042 \\
\hline Poor adherence & 221 & 94.4 & 50 & 75.8 & $<0.001$ \\
\hline Diabetic retinopathy & 3 & 1.3 & 0 & 0.0 & - \\
\hline \multicolumn{6}{|l|}{ Treatment received } \\
\hline Insulin & 157 & 67.1 & 39 & 59.1 & 0.145 \\
\hline Glibenclamide & 63 & 26.9 & 24 & 36.4 & 0.092 \\
\hline Metformin & 55 & 23.5 & 23 & 34.8 & 0.047 \\
\hline Regular intake of treatment & 226 & 96.6 & 65 & 98.5 & 0.375 \\
\hline Session deemed useful & 225 & 96.2 & 66 & 100.0 & 0.103 \\
\hline Frequency of visits/month & & & & & 0.008 \\
\hline$<2$ & 217 & 92.7 & 41 & 62.1 & - \\
\hline$\geq 2$ & 17 & 7.3 & 25 & 37.9 & - \\
\hline
\end{tabular}

TABLE 4: Determinants of poor glycaemic control in the multivariate analysis.

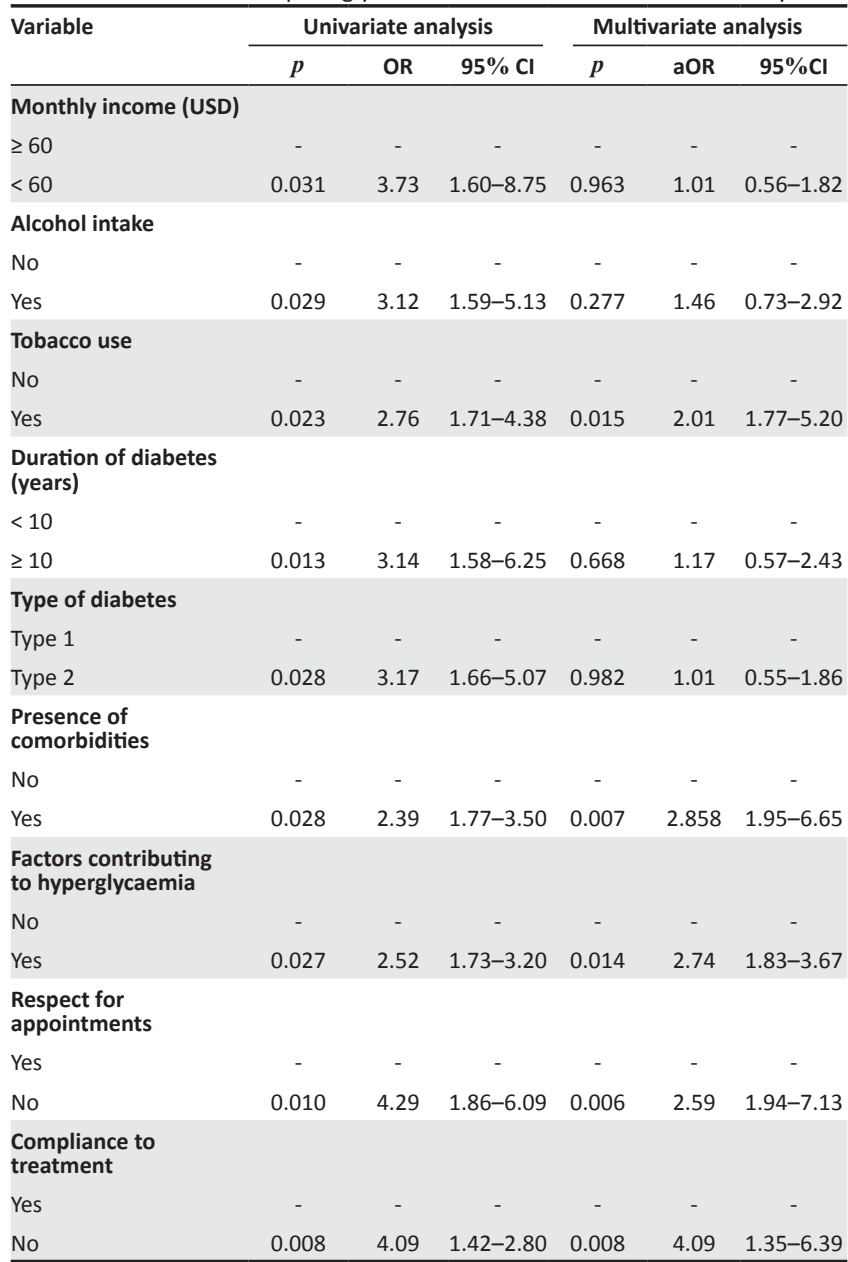

aOR, adjusted odds ratio; $\mathrm{Cl}$, confidence interval; OR, odds ratio; USD, United States dollars.

\section{Discussion}

More than three-quarters of our participants had poor glycaemic control. The independent determinants of poor glycaemic control were smoking, the presence of comorbidities, the presence of a factor contributing to hyperglycaemia, non-respect of appointment schedules and non-adherence to treatment.

The prevalence of poor glycaemic treatment, based on the glycosylated haemoglobin assay, was $78 \%$. Our observation corroborates that made by several authors, notably in Brazil and Africa. ${ }^{20,21}$ It is lower than the $86 \%$ reported by GebreYohannes and colleagues in Ethiopia. ${ }^{22}$ On the other hand, it is higher than the $60.5 \%$ and $68.0 \%$ found by LongoMbenzaand colleagues and Otienoand colleagues in the DRC and Kenya, respectively. ${ }^{15,23}$ The disparity in the prevalence between studies may be explained by the differences in sample size, the methodology and the populations' characteristics, as well as the definitions of glycaemic treatment and the statistical methods used.

In our study, smoking was a determinant of poor glycaemic control. Diabetics with a history of smoking were twice more likely to have poor glycaemic control than nonsmokers. Our observation is similar to that of Melinand 
colleagues $^{24}$; however, the association of smoking with poor glycaemic control is not consistent in all available studies. ${ }^{25,26}$ Tobacco may negatively affect glycaemic control by stimulating the sympathetic system responsible for glycogenolysis and gluconeogenesis ${ }^{27}$ and stimulating the renin-angiotensin system on the basis of post-receptor insulin resistance. ${ }^{28}$

The presence of comorbidities was a determinant of poor glycaemic control in our study; patients with comorbidities were almost three times as likely to be uncontrolled compared to those without comorbidities. It is established that the presence of comorbidities causes stimulation of the production of counter-regulation hormones, particularly cortisol, through the stress they induce..$^{29}$

Non-respect of scheduled appointments was associated with poor glycaemic control, increasing the risk of poor control by three in our sample. Rhee and colleagues showed that diabetic patients with at least one annual visit were more adherent to their medication and had an average $\mathrm{HbA} 1 \mathrm{c}$ lower $(7.6 \%)$ compared to those without annual visits (HbA1c: 9.7\%). ${ }^{30}$

In Venezuela, satisfaction with the treatment of diabetes was associated with good glycaemic control in a study done by Moreira and colleagues ${ }^{31}$ but not with attendance in a therapeutic education programme. Medical monitoring strengthens and contributes to the self-management maintenance of diabetics, thus promoting better glycaemic control.

In our study, patients not adhering to treatment were four times more likely to have poor glycaemic control compared to those adhering. Our observation corroborates that of Kakoma and colleagues, ${ }^{32}$ who, in a study conducted in Lubumbashi, DRC, reported poor adherence as the main factor in the decompensation of diabetes $(29.4 \%) . .^{30}$

The presence of a factor contributing to hyperglycaemia is a determinant of poor glycaemic control, which multiplies this risk by three. This observation corroborates that made by Maâlej and colleagues of a strong association between the imbalance of diabetes and the presence of a factor contributing to hyperglycaemia, in particular, pulmonary infection with a multiplication of the risk of occurrence of two to six times. ${ }^{33}$ The infection represents stress to the body, and the stress response leads to the activation of the sympathetic system with the release of hyperglycaemic catecholamines. ${ }^{28}$

Diabetes is increasing in importance in our settings with few resources for health and health systems directed to other priorities; working to achieve an adequate glycaemic control for diabetic patients through cost-effective interventions is crucial. Most of the factors identified in our study, such as smoking, adherence to treatment and respect of schedules, could be modified through effective education.
The interpretation of our results must take into account some limitations. Not all factors recognised as being important predictors of glycaemic control in Africa have been assessed in this study, for example diet, exercise and diabetes education. ${ }^{18}$ As a cross-sectional study, it cannot establish a cause-and-effect relationship between the different variables of interest. The small size of the sample does not allow identification of the additional associations between the different variables of interest. The unique HBA1c assay should, given the variability of biological parameters, underor overestimate the prevalence of poor glycaemic control. The hospital setting does not make it possible to generalise the results of this study to all patients with diabetes in Vanga. Nevertheless, the strength of this study is having generated preliminary data on glycaemic control in a rural environment, which often is not taken into account in health programmes because of the lack of data.

Future research should look for other factors related to glycaemic control, such as genes or therapeutic schemes available, and moreover define health strategies to improve control amongst diabetic patients.

\section{Conclusion}

This study showed that more than three-quarters of diabetics undergoing treatment are not controlled, with patient-related factors as the main explanatory factors for this poor glycaemic control. Therefore, the establishment of a therapeutic education programme and wider integration of diabetes care services mainly at the primary level of the healthcare pyramid should contribute to improved diabetes treatment.

\section{Acknowledgements}

The authors thank Manase Lusuami, who supported the study with lab technical assistance using the university lab services.

\section{Competing interests}

The authors declare that they have no financial or personal relationships that may have inappropriately influenced them in writing this article.

\section{Author's contributions}

L.M.C., J-P.F.L., L.B.F., O.A.G. and L.N.P. contributed to the design and implementation of the research, to the analysis of the results and to the writing of the manuscript.

\section{Funding information}

This research received no specific grant from any funding agency in the public, commercial or not-for-profit sectors.

\section{Data availability}

Data sharing is not applicable to this article as no new data were created or analysed in this study. 


\section{Disclaimer}

The views and opinions expressed in this article are those of the authors and do not necessarily reflect the official policy or position of any affiliated agency of the authors.

\section{References}

1. World Health Organization (WHO). Global report on diabetes. Geneva: WHO, 2016; $21 \mathrm{p}$

2. Mutyambizi C, Pavlova M, Chola L, Hongoro C, Groot W. Cost of diabetes mellitus in Africa: A systematic review of existing literature. Global Health. 2018;14(1):3. https://doi.org/10.1186/s12992-017-0318-5

3. Mbanya J-C, Motala A, Sobngwi E, Assah F, Enoru S. Diabetes in sub-Saharan Africa. Lancet. 2010;375(9733):2254-2266. https://doi.org/10.1016/S0140-6736 (10)60550-8

4. Sobngwi E, Mauvais-Jarvis F, Vexiau P, Mbanya J-C, Gautier J-F. Diabetes in Africans. Part 1: Epidemiology and clinical specificities. Diabetes Metab. 2001;27(6):628-634.

5. Mense K, Mapatano A, Mutombo P, Muyer M-C. [A case-control study to determine the sources of noncompliance to medical monitoring in diabetic patients in Kinshasa in 2010]. Pan Afr Med J. 2014;17(1):258. https://doi org/10.11604/pamj.2014.17.258.2892

6. Muyer M-C, Muls E, Buntinx F, Mapatano A, Bieleli E, Okitolonda W. [Diabetes mellitus in Sub-Saharan Africa, a systematic review of the literature]. Louvain Médical. 2008;127(1):153-165.

7. Muyer M, Muls E, Mapatano A, et al. Diabetes and intermediate hyperglycaemia in Kisantu, DR Congo: A cross-sectional prevalence study. BMJ Open. 2012;2(1) e001911. https://doi.org/10.1136/bmjopen-2012-001911

8. Katchunga P, Malanda B, Mweze MC, et al. [Knowledge of the general population about hypertension and diabetes mellitus in South Kivu, Democratic Republic of about hypertension and diabetes mellitus in South Kivu, Democratic Republic of
Congo]. Rev Epidemiol Sante Publique. 2012;60(2):141-147. https://doi. org/10.1016/j.respe.2011.10.005

9. Sabaté E. Adherence to long-term therapies: Evidence for action [homepage on the Internet]. Geneva: World Health Organization; 2003 [cited 2019 Jul 2]. Available from: http://www.who.int/chronic_conditions/adherencereport/en/.

10. Doubi S, El Ouahabi H, Dakkar O, Ajdi F. [Evaluation of a therapeutic education program in diabetic patients in a Moroccan university hospital: Preliminary results of a pilot survey]. Pan Afr Med J. 2014;18(1):258. https://doi.org/10.11604/ pamj.2014.18.258.3054

11. Nathan $D$. The diabetes control and complications trial/epidemiology of diabetes interventions and complications study at 30 years: Overview. Diabetes Care. 2014;37(1):9-16. https://doi.org/10.2337/dc13-2112

12. Shorr R, Franse L, Resnick H, Di Bari M, Johnson K, Pahor M. Glycemic control of older adults with type 2 diabetes: Findings from the Third National Health and Nutrition Examination Survey, 1988-1994. J Am Geriatr Soc. 2000;48(3):264-267. https://doi.org/10.1111/j.1532-5415.2000.tb02644.x

13. Lecomte P, Romon I, Fosse S, Simon D, Fagot-Campagna A. Self-monitoring of blood glucose in people with type 1 and type 2 diabetes living in France: The Entred study 2001. Diabetes Metab. 2008;34(3):219-226. https://doi.org/10.1016/ j.diabet.2007.11.005

14. Sobngwi E, Ndour-Mbaye M, Boateng K, et al. Type 2 diabetes control and complications in specialized diabetes care centres of six sub-Saharan African countries: The Diabcare Africa study. Diabetes Res Clin Pract. 2012;95(1):30-36. https://doi.org/10.1016/j.diabres.2011.10.018

15. Longo-Mbenza B, Mvitu-Muaka M, Mbenza G, Mbungu-Fuele S, Nzuzi V, Mbadi-ASungu A. Risk factors of poor control of HBA1c and diabetic retinopathy: Paradox with insulin therapy and high values of HDL in African diabetic patients. Int J Diabetes Metab. 2008;16(1):69-78.
16. Kamuhabwa A, Charles E. Predictors of poor glycemic control in type 2 diabetic patients attending public hospitals in Dar es Salaam. Drug Healthc Patient Saf. 2014;6(1):155-165. https://doi.org/10.2147/DHPS.S68786

17. Demoz G, Gebremariam A, Yifter H, et al. Predictors of poor glycemic control among patients with type 2 diabetes on follow-up care at a tertiary healthcare setting in Ethiopia. BMC Res Notes. 2019;12(1):207. https://doi.org/10.1186/ s13104-019-4248-6

18. Mbanya J-C, Aschner P, Gagliardino JJ, et al. Factors associated with achievement of glycemic goal in Africa-Results from the International Diabetes Management Practices Study (IDMPS). Diabetes. 2018;67(Suppl 1):2399-PUB. https://doi.org/ 10.2337/db18-2399-PUB

19. Banza P. The profile of patients diagnosed with type 2 diabetes mellitus at Vanga hospital, DRC [unpublished dissertation]. Pretoria: University of Limpopo; 2012.

20. Lumeya S, Fina J-P, Lepira F, Kaimbowa K, Kintaudi L, Lukanu P. [Prevalence and determinants of ocular complications of diabetes at the Vanga General Reference Hospital, Bandundu Province, DRC]. Revue médicale des Grands Lacs. 2017;8(1):43-50.

21. Mendes AB, Fittipaldi JA, Neves R, Chacra A, Moreira E, Jr. Prevalence and correlates of inadequate glycaemic control: Results from a nationwide survey in 6671 adults with diabetes in Brazil. Acta Diabetol. 2010;47(2):137-145. https:// doi.org/10.1007/s00592-009-0138-z

22. Gebre-Yohannes A, Rahlenbeck S. Glycaemic control and its determinants in diabetic patients in Ethiopia. Diabetes Res Clin Pract. 1997;35(2-3):129-134. https://doi.org/10.1016/s0168-8227(96)01367-8

23. Otieno F, Kariuki M, Ng'ang'a L. Quality of glycaemic control in ambulatory diabetics at the out-patient clinic of Kenyatta National Hospital, Nairobi. East Afr Med J. 2003;80(8):406-410. https://doi.org/10.4314/eamj.v80i8.8731

24. Melin E, Thunander M, Svensson R, Landin-Olsson M, Thulesius H. Depression obesity, and smoking were independently associated with inadequate glycemic control in patients with type 1 diabetes. Eur J Endocrinol. 2013;168(6):861-869. https://doi.org/10.1530/EJE-13-0137

25. American Diabetes Association. Standards of medical care in diabetes - 2014 Diabetes Care. 2014;37(Suppl 1):S14-S80. https://doi.org/10.2337/dc14-S014

26. Kuo C-K, Lin L-Y, Yu Y-H, Chang C-H, Kuo H-K. A family history of diabetes mellitus is associated with poor glycemic control and increased metabolic risks among people with diabetes: Data from the National Health and Nutrition Examination. Intern Med. 2010;49(6):549-555. https://doi.org/10.2169/internalmedicine. Intern Med
49.2880

27. Johnson E, Kamilaris T, Chrousos G, Gold P. Mechanisms of stress: A dynamic overview of hormonal and behavioural homeostasis. Neurosci Biobehav Rev. 1992;16(2):115-130. https://doi.org/10.1016/s0149-7634(05)80175-7

28. Vigouroux C, Magré J, Desbois-Mouthon C, et al. [Major insulin resistance syndromes: Clinical and pathophysiology]. J Soc Biol. 2001;195(3):249-257.

29. Duric V, Clayton S, Leong M, Li-Lian Y. Comorbidity factors and brain mechanisms linking chronic stress and systemic illness. Neural Plast. 2016;2016(1):5460732. https://doi.org/10.1155/2016/5460732

30. Rhee $M$, Slocum W, Ziemer D, et al. Patient adherence improves glycemic control. Diabetes Educ. 2005;31(2):240-250. https://doi.org/10.1177/0145721 705274927

31. Moreira E, Jr, Neves R, Nunes Z, et al. Glycemic control and its correlates in patients with diabetes in Venezuela: Results from a nationwide survey. Diabetes Res Clin Pract. 2010;87(3):407-414. https://doi.org/10.1016/j.diabres.2009. 12.014

32. Kakoma P, Kadiebwe D, Mbuyu A, Makonga P, Bugeme M, Mukuku O. [Diabetic ketoacidosis in adults at the Sendwe Hospital in Lubumbashi: About 51 cases]. Pan Afr Med J. 2014;17(1):324. https://doi.org/10.11604/pamj.2014.17 324.3545

33. Maâlej S, Belhaoui $N$, Bourguiba $M$, et al. [Pulmonary tuberculosis causes an imbalance of diabetes: Retrospective study of 60 patients in Tunisia]. Presse Med. 2009;38(1):20-24. https://doi.org/10.1016/j.Ipm.2008.05.011 